\title{
CROSS-SECTIONAL STUDY TO ASSESS AND GRADE THE QUALITY OF DONOR CORNEAL MATERIAL
}

\author{
N. H. Patel1, Sahil Bajaj2, Amandeep Chawla 3 , Saurabh Bothra ${ }^{4}$ \\ 1 Professor and HOD, Department of Ophthalmology, R. D. Gardi Medical College, Ujjain. \\ ${ }_{2}^{2}$ nd Year Junior Resident, Department of Ophthalmology, R. D. Gardi Medical College, Ujjain. \\ ${ }^{3} 3^{\text {rd }}$ Year Junior Resident, Department of Ophthalmology, R. D. Gardi Medical College, Ujjain. \\ ${ }^{4} 1^{\text {st }}$ Year Junior Resident, Department of Ophthalmology, R. D. Gardi Medical College, Ujjain.
}

\section{ABSTRACT}

Proper evaluation of donor cornea is critical to the success of corneal transplantation. Attention must be paid to the cause of death and ocular condition as several general and ocular diseases constitute contraindications for donor corneal usage. Death to enucleation time should be noted. Gross examination and slit lamp biomicroscopy are mandatory for the evaluation of the donor eye, while specular microscopy adds another useful dimension to information regarding donor cornea.

\section{KEYWORDS}

Specular Microscopy Enucleation, McCarey Kaufman.

HOW TO CITE THIS ARTICLE: N. H. Patel, Sahil Bajaj, Amandeep Chawla, Saurabh Bothra. "Cross-Sectional Study to Assess and Grade the Quality of Donor Corneal Material". Journal of Evolution of Medical and Dental Sciences 2015; Vol. 4, Issue 101, December 17; Page: 16593-16595, DOI: 10.14260/jemds/2015/2473

\section{INTRODUCTION}

Proper evaluation of donor cornea is critical to the success of corneal transplantation. Attention must be paid to the cause of death and ocular condition as several general and ocular diseases constitute contraindications for donor corneal usage. Death to enucleation time should be noted. Gross examination and slit lamp biomicroscopy are mandatory for the evaluation of the donor eye while specular microscopy adds another useful dimension to information regarding donor cornea.

In recent years, the number of donor corneas procured by eye banks is steadily increasing all over the world. Safety and viability of the donor cornea is an essential prerequisite for successful outcome of corneal transplant procedure. The medical standards and quality control measures followed by eye banks largely determine the quality of cornea supplied for surgery.

The infrastructure should be optimal and the technical manpower should be properly trained in all aspects of eye banking.

Transplantation of human cornea involves potential risks of transmission of host disease to recipient and unsuccessful outcome because of poor quality of donor cornea or other complications. From extensive clinical and laboratory evaluations of corneal transplants, it was possible to increase the safety in the choice of donor cornea. Contraindications were based on either significant risk of transmission of disease or poor results. Although criteria for donor selection are more stringent for penetrating grafts, it is possible to be less restrictive for lamellar grafts.

In eye banking all available donor eyes are harvested as a matter of policy except in the case of highly contagious diseases.

The standards followed by the eye bank and the quality

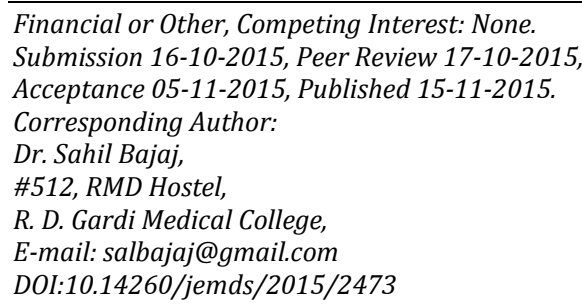

of the tissue obtained is of paramount importance in reducing the incidence of endophthalmitis caused by contaminated donor tissue. The incidence of positive donor corneoscleral rim contamination varies from $12 \%$ to $47 \%$. The isolates included Staphylococcus aureus, Staphylococcus epidermidis, hemolytic and non-hemolytic Streptococci, Pseudomonas and Propionibacterium. Donor corneas have a significantly higher incidence of Streptococcus and gram negative bacteria in cultures.

Numerous studies indicate that the occurrence of post penetrating keratoplasty endophthalmitis is far less than the frequency of positive cultures. A large population of bacteria are eliminated by techniques like donor eye immersion in antibacterial solutions, tissue preservation in media containing antibiotics, antibiotics administered intra- and postoperatively and finally the host immune mechanisms.

\section{Diseases Transmissable by Corneal Transplantation \\ - Rabies \\ - Hepatitis B \\ - Creutzfeldt-Jakob disease \\ - Retinoblastoma \\ - Bacterial/Fungal keratitis \\ - Bacterial/Fungal endophthalmitis}

Corneal transplantation is the most commonly performed of all types of organ transplantation and is successful for visual rehabilitation of the corneal blind. Quality control is fundamental to success of corneal transplantation.

\section{AIM OF STUDY}

To Assess the Quality of Donor Corneal Material.

\section{Design of Study \\ Cross-sectional study.}

\section{MATERIAL AND METHOD}

In a cross-sectional study, 120 donor corneal tissues of 60 donors were evaluated between April 2011 and April 2015 in the eye bank, R. D. Gardi Medical College. While collecting the donor tissue material, standard protocol was followed. Donor tissue [Corneo sclera rim, $3-4 \mathrm{~mm}$ in size was dissected and 
preserved in McCarey Kauffman media] and tissue evaluated the same day in the following manner.

\section{Gross Examination}

The eyes of the donor were examined with a bright torch, corneo-scleral segment is examined grossly for clarity, epithelial defects, foreign objects, arcus senilis, striations due to folding in Descemet's membrane, abnormal corneal shape, abnormal anterior segment anatomy (Aphakia, Pseudophakia, refractive surgery) contamination and scleral color.

The color of the tissue storage media is noted. If contents are colorless or yellowish in color it indicates an acidic PH, which could be due to microbial contamination. The expiry date of the storage media mentioned on the vial is noted.

\section{Biomicroscopic Examination}

The glass vials are placed in a special holder and viewed conveniently in a mirror placed below the vial or a special corneal storage viewing chamber provides a good view of the excised rim

\section{Cornea}

\section{Epithelium}

For oedema, defects, exposure, trauma and foreign bodies. Epithelial oedema is indicative of poor endothelial function. Epithelial oedema has to be carefully differentiated from surface irregularity of the epithelium by oblique illumination or retroillumination techniques.

\section{Stroma}

For arcus senilis, corneal scars, corneal infiltrates, abnormal corneal shape/size, e.g.: keratoconus.

\section{Endothelium}

For keratic precipitates, central guttata The specular endothelial reflection provides a gross estimate of the endothelium in terms of cell density, pleomorphism and presence of guttata. A drop or two of antibiotic solution on the surface of the cornea will improve endothelial viewing. Frequently, linear markings similar to snail tracks are seen on the endothelium. These are stress fractures of the endothelial sheet from the trauma of excision.

\section{Grading of the Corneal Tissue}

A suggested scale for evaluating a cornea ranges from excellent to unacceptable for transplant. A number corresponding to the evaluation from $0-4$ is assigned with 0 being the best and 4 being the worst. Alternately, severity of defect may be expressed as none, slight, moderate, and heavy.

e) Fair endothelium (Marked defects, low cell density, vacuolated cells).

f) Technical problem in removal.

\section{SPECULAR MICROSCOPY}

We evaluated the donor corneal buttons for the endothelial cell count. The normal endothelium shows a pattern of cells of similar size and shape with no abnormal dark or bright structures. The cell density is between 2000 and 3500 cells $/ \mathrm{mm}^{2}$. Specular viewing of endothelium helps in better selection of corneas.
Whatever tissue rating system is used, its application always will be subjective to some degree because of the qualitative nature of selected criteria.

\section{CATEGORIES ARE AS FOLLOWS}

\section{Excellent [GRADE 1]}
a) No epithelial defects.
b) Crystal clear stroma (0-1).
c) No arcus senilis.
d) No folds in Descemet's membrane (0-1).
e) Excellent endothelium (no defects).
f) No vacuolated cells.

\section{Very Good [GRADE 2]}

a) Slight epithelial haze or defects.

b) Clear stroma (1-2).

c) Very slight arcus.

d) Few light folds (1-2).

e) Very good to excellent endothelium (no defects).

f) No vacuolated cells.

\section{Good [GRADE 3]}

a) Obvious moderate epithelial defects.

b) Light to moderate cloudiness (2-3).

c) Moderate arcus senilis $<2.5 \mathrm{~mm}$.

d) Obvious folds (Numerous, but shallow) (2-3).

e) Good endothelium.

f) Few vacuolated cells (None within $8 \mathrm{~mm}$ of central cornea).

\section{Fair [GRADE 4]}

a) Obvious epithelial defect ( $>60 \%$ ).

b) Moderate to heavy stromal cloudiness (3-4).

c) Heavy folds (Numerous, deep, central) (3-4).

d) Heavy arcus senilis $>2.5 \mathrm{~mm}$.

e) Fair to good endothelium (Moderate endothelial defect, vacuolated cells, low cell density).

f) Moderate vacuolated cells (Some central).

\section{Not suitable for surgery [GRADE 5]}

a) Moderate vacuolated cells (Some central).

b) Severe stromal cloudiness (4+).

c) Marked folds (Heavy, numerous, central) (4+).

d) Numerous central corneal vacuolated cells.

\section{OBSERVATION AND DISCUSSION}

\begin{tabular}{|c|c|}
\hline Age & Number of Eyes \\
\hline $10-20$ & 3 \\
\hline $20-30$ & 1 \\
\hline $30-40$ & 3 \\
\hline $40-50$ & 23 \\
\hline$>60$ & 80 \\
\hline
\end{tabular}

\begin{tabular}{|c|c|}
\hline $\begin{array}{c}\text { Time of Enucleation } \\
\text { (In Hours) }\end{array}$ & Number of Eyes \\
\hline $1-2$ & 8 \\
\hline $2-4$ & 40 \\
\hline $4-6$ & 62 \\
\hline
\end{tabular}



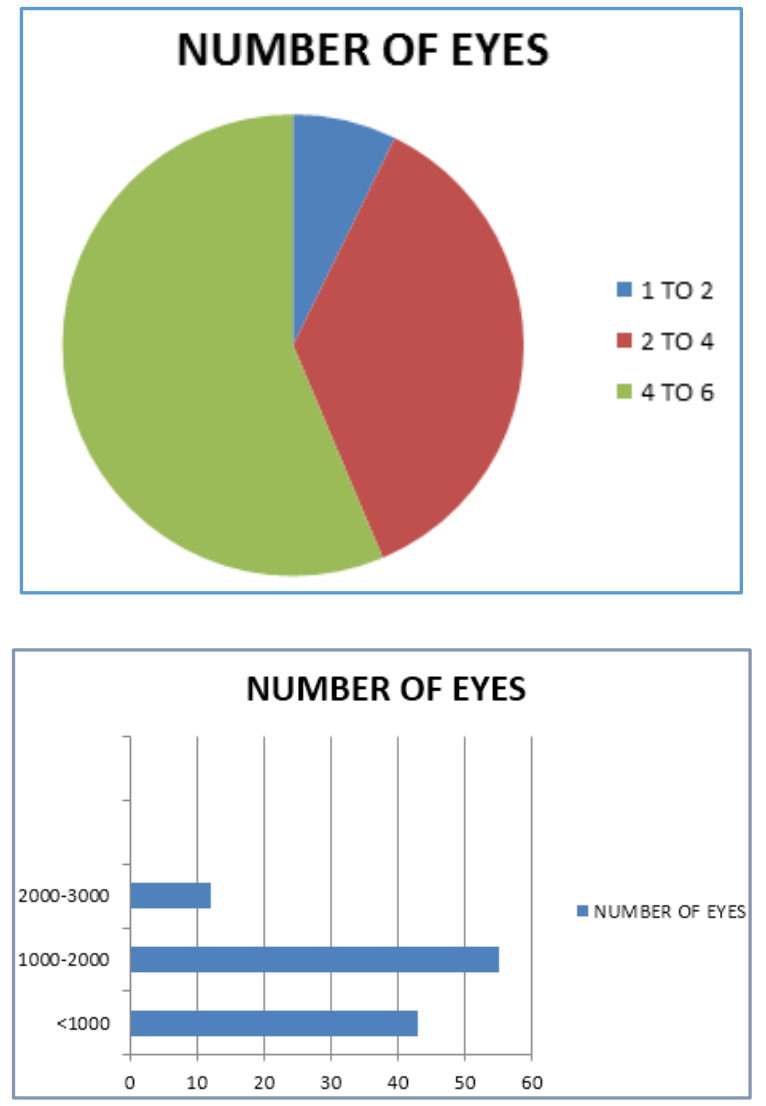

\begin{tabular}{|c|c|}
\hline Cause of Death & $\begin{array}{c}\text { Number of } \\
\text { Eyes }\end{array}$ \\
\hline Cardiopulmonary arrest & 85 \\
\hline Trauma & 23 \\
\hline Myocardial infarction & 2 \\
\hline
\end{tabular}

\begin{tabular}{|c|c|}
\hline $\begin{array}{c}\text { Specular Endothelial } \\
\text { Count }\end{array}$ & $\begin{array}{c}\text { Number of } \\
\text { Eyes }\end{array}$ \\
\hline$<1000$ & 43 \\
\hline $1000-2000$ & 55 \\
\hline $2000-3000$ & 12 \\
\hline
\end{tabular}

\begin{tabular}{|c|c|}
\hline Grading of Corneal Tissue & $\begin{array}{c}\text { Number of } \\
\text { Eyes }\end{array}$ \\
\hline Excellent & 11 \\
\hline Very Good & 25 \\
\hline Good & 28 \\
\hline Fair & 33 \\
\hline Not suitable for surgery & 13 \\
\hline
\end{tabular}

\section{CONCLUSION}

- The most common cause of death was cardiopulmonary arrest.

- Out of 110 donor buttons, 11 were excellent, 25 were very good, 28 were good, 33 were fair and 13 were not suitable for surgery. Specular endothelial count between 1000-2000 cells per $\mathrm{mm}^{2}$ was seen in 55 eyes followed by $<1000$ cells in 43 and 2000 to 3000 in 12 eyes.

\section{REFERENCES}

1. Saini, et al. Donor corneal tissue evaluation. IJO 1996, vol. 44, Page 3-13.

2. Liaboe C, Vislisel JM, Schmidt GA, Greiner MA. Corneal Transplantation: From Donor to Recipient. May 19, 2015.

3. Aneeta Jabbar, et al. Quality control of corneal tissue processed and issued by a reference eye bank. Kerala journal of ophthalmology, vol XXIV, No.1. March 2012. 